\title{
SITUAÇÕES PERIFÉRICAS
}

\section{Etnografia comparada de pobrezas urbanas}

\author{
RONALDO DE ALMEIDA \\ TIARAJÚ D' ANDREA \\ DANIEL DE LUCCA
}

\begin{abstract}
RESUMO
Este artigo discute a articulação entre pobreza urbana e desigualdade social com base em estudos etnográficos realizados na cidade de São Paulo. Partimos da constatação de que estão em curso melhorias materiais entre a população considerada pobre, mas isso não afeta a reprodução das distâncias sociais. Por meio da comparação de três pesquisas etnográficas, propomos sistematizar e discutir alguns mecanismos sociais comuns que geram essa oscilação entre atenuação da pobreza e reprodução da desigualdade.
\end{abstract}

PALAVRAS-CHAVE: pobreza urbana; desigualdade social; violência

simbólica; vínculos sociais.

\section{SUMMARY}

This article discusses the connection between urban poverty and social inequality, based on ethnographical studies in the city of São Paulo. We start from the statement that there are actual improvements in the material conditions among the population considered poor, but the reproduction of social distances stay untouched. Based on a comparison of three different cases, we try to discuss a few social mechanisms that are in the origins of this variation between relief of poverty and reproduction of inequalities.

KEYWORDS: urban poverty; social inequality; symbolic violence; social bonds.

[1] Este artigo foi produzido a partir dos resultados das pesquisas "Desenvolvimento regional e desigualdades socioprodutivas: tendências recentes, redefinições conceituais e desdobramentos em termos de políticas públicas" do convênio Cebrap/ IPEA, que conta com financiamento da Finep, e "Sociabilidade e Desigualdade" do projeto CEM, que conta com financiamento da Fapesp.

[2] Agradecemos os cuidadosos comentários e sugestões a este texto feitos por Fernando Pinheiro, Fernando Limongi e as discussões do nosso grupo de estudos sobre desigualdade e sociabilidade, que conta ainda com Isabel Georges, Edlaine Gomes, Gabriel Feltran e Felipe Hévia.

\section{INTRODUÇÃO ${ }^{2}$}

Este artigo discute a articulação entre pobreza urbana e desigualdade social com base em estudos etnográficos realizados na cidade de São Paulo. A literatura, sobretudo a sociológica e a econômica, já demonstrou que estes dois processos não caminham necessariamente no mesmo sentido, uma vez que pode ocorrer a diminuição da pobreza e o aumento da desigualdade ou o aumento daquela e a diminuição desta, entre outras possibilidades. Para as pretensões deste texto, partimos da constatação de que estão em curso melhorias materiais entre a população considerada pobre, mas também está em curso a reprodução de distâncias sociais, algo que pode ser estendido para outros centros urbanos brasileiros. Por meio da comparação de três pesquisas etnográficas, propomos sis- 
tematizar e discutir alguns mecanismos sociais que produzem esta oscilação entre atenuar e reproduzir, cujos efeitos e causas são tanto materiais quanto simbólicos.

A configuração atual da região metropolitana de São Paulo é o resultado, em grande medida, de um processo socioeconômico que remonta a meados do século XX. De forma resumida, a industrialização da região Sudeste do país a partir dos anos 1950 foi um dos fatores geradores do forte processo de migração, sobretudo de nordestinos que fugiam de situações de pobreza em busca de trabalho e renda. No Sudeste, eles encontraram empregos nas indústrias nascentes, na expansão da construção civil, nos domicílios das classes média e alta, no pequeno comércio de bairro ou no comércio ambulante das zonas de maior fluxo urbano. Se do ponto de vista do emprego e da renda houve um ganho em relação à vida anterior, um dos corolários da migração foi a ocupação das regiões periféricas das grandes cidades; em São Paulo, os migrantes foram mais em direção às Zonas Leste e Sul, onde encontraram péssimas condições de habitação nas áreas de expansão da mancha urbana³.

O cenário atual difere do início da industrialização. A região que era considerada periferia de São Paulo nos anos 1970 e 1980 sofreu várias mudanças, adquirindo melhorias urbanas como asfalto, transporte público, saneamento básico, além de serviços públicos de saúde e educação, mesmo que precários ${ }^{4}$. Somados a isto, mais recentemente, os programas sociais da década de 1990 e 2000 atingiram muitas famílias pobres e as regiões onde elas habitam, mesmo sendo em uma área urbana de São Paulo em que o impacto é menor do que na zona rural5. Assim, do ponto de vista de certos indicadores, os contextos de pobreza vêm apresentando significativas melhorias sociais. Entretanto, considerando outros fatores, constata-se a piora da vida nestas regiões. O primeiro é o aumento da violência: a possibilidade de entrar no tráfico ou de ser vítima das várias formas de violência (seja dos bandidos, seja da polícia) mesmo não entrando no tráfico de drogas ${ }^{6}$. O segundo é a qualidade dos vínculos das relações de trabalho que se caracteriza estruturalmente pela transição entre o emprego formal e a informalidade ${ }^{7}$. Por fim, o aumento do contingente populacional que amplia as novas "fronteiras urbanas"8.

Este artigo caminha em duas direções, que, no seu decorrer, irão se alternando: refletirá sobre algumas formas de atenuação da pobreza mas também acerca da reprodução de outras precariedades. E uma vez que a metrópole paulista há muito tempo é, em termos absolutos, concentradora de riqueza no Brasil, a persistência de precariedades tem como causa e conseqüência a reprodução das distâncias sociais.A nossa hipótese é que estes dois vetores com sentidos contrários estão
[3] Caldeira, Teresa. Cidade de muros. São Paulo: Editora 34/Edusp, 200o; Bonduki, Nabil. Origens da habitação social no Brasil. São Paulo: Estação Liberdade/Fapesp, 1998.

[4] Marques, Eduardo e Torres, Haroldo. Segregação, pobreza e desigualdades socais. São Paulo: Senac, 2005.

[5] Esteé um tema que acreditamos ainda necessitar de mais pesquisas com ênfase em metodologia qualitativa. Mais precisamente, qual o impacto dos programas sociais de transferência de renda na vida das famílias? Como elas gerem o recurso recebido? Qual o impacto no orçamento doméstico? Quais práticas políticas envolvem a transferência de renda e quais derivam dela?

[6] Zaluar, Alba. O condomínio do diabo. Rio de Janeiro: Revan/UFRJ, 1994; Telles, Vera da Silva e Cabanes, Robert (orgs.). Nas tramas da cidade: trajetórias urbanas e seus territórios. São Paulo: Associação Editorial, Humanitas, IRD, 2006; Feltran, Gabriel de Santis. Fronteiras de tensão: um estudo sobre política e violência nas periferias de São Paulo. Campinas: tese de doutorado, Faculdade de Ciências Sociais, Unicamp, 2008.

[7] Guimarães, Nadya A. "Trabalho em transição". Novos Estudos, n 76 , novembro de 2006.

[8] Torres caracteriza as regiões pobres de São Paulo a partir de uma classificação segundo a qualidade da urbanização: "periferia precária", "periferia consolidada" e "periferia em expansão". Torres, Haroldo. "A fronteira paulistana" In: Marques e 
Torres, op. cit.

[9] Certeau, Michel de. A invenção do cotidiano. 2 vols. Petrópolis: Vozes, 2003.

[10] Entendemos como "centro expandido" a área definida pela Secretaria de Trânsito de São Paulo: algo maior do que o centro comercial e histórico, e onde ocorre a maior circulação de automóveis da cidade de São Paulo. Nesta área verifica-se alta circulação de transportes, mercadorias, capital financeiro, oferta de postos de trabalho $e$ atividades culturais, dentre outras. Fora do "centro expandido", o Tatuapé (bairro de classe média alta da Zona Leste) eo condomínio de Alphaville são alguns dos vetores de "centralidades" de São Paulo. articulados em um mesmo processo social, cuja resultanteé o equacionamento entre atenuar e reproduzir.

Compreendemos esta equação a partir da articulação de mecanismos sociais transversais aos diferentes universos empíricos observados. Tais mecanismos resultaram da análise comparativa de três pesquisas etnográficas desenvolvidas em interlocução umas com as outras. As semelhanças mais específicas entre os campos etnográfi$\cos$ (como o perfil socioeconômico) não formaram o critério inicial de seleção dos universos de observação. Ao contrário, procuramos diversificar os casos sem o objetivo de produzir uma representatividade do tipo amostral. O método etnográfico, ainda mais quando efetuado em espaços de dimensões metropolitanas, não permite (e nem se propõe a) definir padrões estatísticos, mas possibilita aferir, pelo contraste, alguns mecanismos comuns às situações que nos propusemos investigar. São eles: a violência simbólica, a vulnerabilidade política e a qualidade dos vínculos sociais.

$\mathrm{Na}$ verdade, adotamos como plano de comparação as diferentes "situações periféricas" diante das "centralidades" sociais na produção e circulação de bens materiais e simbólicos. O que chamamos de "situações periféricas" não se refere a um estado de exclusão, mas a contextos sociais em que há acesso precário a melhorias materiais e a recursos simbólicos. O termo "periférico" deve-se ao fato de o "foco" empírico estar na posição hierarquicamente inferior do espaço social, distante das centralidades da produção e reprodução de bens materiais e simbólicos com maior valor social. Neste sentido, a distinção analítica entre estratégia e tática feita por Certeau parece-nos frutífera para pensar a estruturação do espaço social que situa, na sua periferia, parcelas da população de São Paulo. Certeau distingue dois tipos de ação9: ação estratégica e ação tática. A distinção é sempre relacional e situacional a um ordenamento maior. Diferente da ação estratégica que age a partir de um lugar próprio, a tática age em um lugar subordinado a centralidades na reprodução do espaço social, daí sua posição de fraqueza. A tática é a ação do fraco, aquele que age somente "nos possíveis que lhe se apresenta". Cabe ao mais fraco agir (ou existir) taticamente nas falhas ou limitações de estrutura social cujas regras do jogo social lhes são desfavoráveis.

As "situações" aqui analisadas são: a favela Paraisópolis e o entorno formado pelo rico bairro do Morumbi; o distrito de Cidade Tiradentes e o "centro expandido" de São Paulo ${ }^{10}$; e os moradores de rua no centro comercial de São Paulo. As "situações" foram compreendidas de forma duplamente relacional: cada contexto de pobreza em relação a uma "centralidade" correspondente (e imputada) e a comparação de cada "situação" em relação às outras. Por conseguinte, estas oposições não devem ser substantivadas pelo simples fato de cada localidade e 
seus freqüentadores estarem mais ou menos conectados ao município, mesmo que indiretamente. O objetivo, portanto, não é reduzi-las aos limites geográficos, mas apreendê-las em relação a outros espaços sociais da metrópole paulista como contemplada na idéia de "afastamentos significativos" de Lévi-Strauss ${ }^{11}$.

Bourdieu ${ }^{12}$ adverte sobre os equívocos decorrentes das análises sociais que tendem a naturalizar o espaço social, ficando presas às evidências empíricas daquilo que ocorre no espaço físico escolhido como universo de observação. Não se deve pensar em termos substancialistas, em que as evidências locais circunscrevem o fenômeno, mas na estrutura social que o produziu. O efeito de naturalização está em não perceber que o espaço físico é expressão de realidades sociais duráveis no mundo natural, que são estruturadas, regra geral, sob o código da desigualdade na reprodução material e simbólica da sociedade.E como não há desigualdade social sem desigualdade espacial, as hierarquias se expressam na concentração dos bens ou serviços públicos e privados e na sua reprodução simbólica legítima. Simbólica na medida em que estruturas sociais também convertem-se em estruturas mentais e vice-versa. São categorias de percepção que classificam pessoas e grupos por sinais diacríticos, estilos de vida, valores, gostos etc. Vejamos cada situação.

\section{OS CAMPOS ETNOGRÁFICOS}

\section{PARAISÓPOLIS-MORUMBI}

A expectativa que se tinha, antes de iniciar a pesquisa etnográfica na favela de Paraisópolis, segunda maior do município de São Paulo e localizada ao lado do rico bairro do Morumbi, era de deparar com um lugar extremamente pobre.A percepção visual da localidade explica essa impressão: uma favela circunscrita pela arquitetura dos condomínios de classes média e alta e das mansões do Morumbi. Contudo, quando comparada a outras localidades de São Paulo, constatamos que Paraisópolis é pouco representativa do cenário da pobreza metropolitana, pois possui diversas formas de acesso a recursos materiais em virtude da alta densidade de suas redes de relações e por sua localização privilegiada.

Algumas referências foram importantes na análise de Paraisópolis. Uma delas procurou entender a favela a partir de sua "estrutura de oportunidades", conforme definição de Kaztman e Filgueira' ${ }^{13}$. Trata-se da articulação entre laços comunitários, Estado e mercado de trabalho.A sinergia entre as três dimensões trabalharia a favor da atenuação da pobreza, na medida em que possibilitaria o acesso a recursos, bens e serviços.

Em boa medida, essa sinergia é resultante da relação entre Paraisópolis e o Morumbi. A formação das duas áreas ocorreu conjuntamente; conforme crescia o empreendimento imobiliário no
[11] Lévi-Strauss, Claude. "A noção de estrutura em etnologia". In: Antropologia estrutural. Rio de Janeiro: Tempo Brasileiro, 1989, p.320.

[12] Bourdieu, Pierre. A miséria do mundo. Petrópolis: Vozes, 1997.
[13] Kaztman, Ruben e Filgueira, Carlos. "Marco conceptual sobre activos, vulnerabilidad y estructuras de oportunidades". In: Documento de la Comisión Económica para América Latina y Caribe. Montevideo: Cepal, 1999, p.9. 
[14] Almeida, Ronaldo e D'Andrea, Tiarajú. "Estrutura de oportunidades em uma favela de São Paulo". In: Marques e Haroldo, op. cit.

[15] A referência aqui é o Hospital Israelita Albert Einstein, vizinho da favela, que nela montou um posto de saúde, em que se atende boa parte da população infantil de Paraisópolis.

[16] Lavalle, Adrián e Castello, Graziella. "Associativismo religioso e inclusão socioeconômica". Novos Estudos, $\mathrm{n} \cong 68$, março de 2004 .
Morumbi, dava-se a atração de mão-de-obra para construção civil e, posteriormente, para o comércio e os trabalhos domésticos (seguranças, empregadas, babás etc.) queos condomínios eas mansões demandavam. Em 2003, de acordo com uma pesquisa quantitativa realizada em Paraisópolis, boa parte da mão-de-obra estava empregada, tendo em vista indivíduos com as mesmas características socioeconômicas de outras regiões da cidade. As ocupações eram predominantemente nas áreas da construção civil, do comércio e da prestação de serviços, e pouquíssimas no trabalho industrial14. De forma resumida, o entorno de Paraisópolis constitui-se como um ativo econômico na oferta de postos de trabalho e fonte de recursos advindos também da filantropia religiosa, de ONGs e do movimento de voluntariado:vagas em escolas particulares, cursos profissionalizantes, assistência médica propiciados, em boa medida, por grupos católicos, espíritas e judaicos ${ }^{15}$.

Além do relativo acesso ao mercado de trabalho e aos recursos de assistência social provindos da vizinhança rica, inflecte positivamente sobre Paraisópolis a rede de relações de algumas lideranças locais com grupos políticos que ascenderam ao poder municipal entre $2001 \mathrm{e}$ 2004, o que resultou em várias políticas sociais para a favela. Convém destacar que nas gestões anteriores, entre 1993-2000, dos prefeitos Paulo Maluf e Celso Pitta, Paraisópolis recebeu poucos benefícios em termos de políticas públicas. Ao contrário, estas gestões tinham como projeto para aquela região a remoção da favela para a construção de uma avenida que ligaria o bairro do Morumbi à Marginal do Pinheiros. Como base eleitoral petista, Paraisópolis foi mais beneficiada nas gestões de Luíza Erundina (1989-1992) e Marta Suplicy (2001-2004).

Se este é o quadro das relações externas à favela, internamente Paraisópolis também possui um contexto bastante favorável de atenuação da pobreza. De forma resumida, graças à sua formação, a favela apresenta uma forte rede de laços de vizinhança e parentesco construída no processo de migração da região Nordeste para São Paulo. De acordo com a pesquisa quantitativa realizada em 2003 paralelamente à pesquisa etnográfica, apenas $7 \%$ dos moradores não tinham nenhum parente em Paraisópolis ${ }^{16}$. Além disso, muitos indivíduos ou famílias eram oriundos das mesmas regiões no Nordeste, o que acrescenta às relações de parentesco as relações entre conterrâneos, adensando desta forma as redes de solidariedade. Como conseqüência, boa parte do comércio e das associações locais encontra-se nas mãos dos moradores mais antigos e dos grupos familiares ou de conterrâneos.

Articulada às relações primárias, existe ainda uma forte rede associativa formada por laços religiosos, sobretudo evangélicos, que se destacam como o principal vínculo associativo na favela junto com a Igreja católica ${ }^{17}$. Estas relações se constituem como circuitos de reci- 
procidade pelos quais circulam benefícios materiais, afetivos e cívicos como ajuda mútua, empréstimos de dinheiro, cuidado dos filhos de mães que trabalham fora de casa, informações sobre emprego, solidariedade em situações de doença etc. Em resumo, diferentes favores que são prestados e variam conforme a qualidade dos laços entre as pessoas ${ }^{18}$.

Exatamente por ser muito assistida, por iniciativas privadas e de caráter público, Paraisópolis tornou-se um "laboratório" para ação de ONGs, do poder público e da academia. Em um processo de retroalimentação, os investimentos sociais atraem mais investimentos. Por todas estas características, morar em Paraisópolis, apesar do estigma de ser uma favela, era percebido por muitos habitantes como positivo e, para alguns, como forma de relativa ascensão social ${ }^{19}$.

Convém destacar, no entanto, que estas ações, tanto do terceiro setor quanto da vizinhança rica, deveram-se em boa medida ao fato de Paraisópolis ser considerada uma favela "pacificada", isto é, com baixo índice de violência quando comparada a outras situações semelhantes em São Paulo. A "pacificação" não se deveu propriamente à ação da segurança pública, mas sobretudo à existência de um "poder local" que mantinha à distância a ação de grandes traficantes ou outras ações mais criminosas. Na verdade, uma rede de parentes e conterrâneos migrantes de uma mesma região do Nordeste, sob a liderança de uma espécie de justiceiro, mantinha a "segurança" em Paraisópolis com o uso da violência repressora ${ }^{20}$. A forma de violência imposta em Paraisópolis assemelhava-se a um padrão de relações que se funda mais na fidelidade ao grupo de parentes do que propriamente numa prática de ilícitos como venda de drogas e/ou uso de armamento pesado, como se dá em outros lugares mais violentos e periféricos de São Paulo.

Em Paraisópolis há uma cumplicidade implícita entre o grupo dominante da favela, os agentes políticos, a administração pública, o terceiro setor, a vizinhança rica, as associações internas da favela e os próprios moradores. Segundo uma moradora, cujo marido tinha algumas atividades econômicas legais com o chefe da favela, era uma relação de proteção e de temor: "Tenório [o chefe] é uma bênção para Paraisópolis, mas Deus te livre de precisar dele”. Boa parte dos recursos recebidos por Paraisópolis decorria de uma situação de violência controlada por um "poder local". "Se Paraisópolis encontrou esta forma de organização interna, é melhor do que a violência explícita, e cabe negociar com ela", disse um então vereador de esquerda (posteriormente eleito deputado estadual e federal), que tem Paraisópolis como uma de suas bases. Em resumo, o empowerment de Paraisópolis resultou da sinergia entre setor público, terceiro setor e ações comunitárias (as legais e as ilegais, as lícitas e as ilícitas).
[18] Almeida, R. e D'Andrea, T. “Pobreza e redes sociais em uma favela paulistana". Novos Estudos, n 68 , março de 2004.

[19] Ibidem.

[20] Este grupo se impôs à favela após um período de "guerra" contra outro grupo de migrantes também do Nordeste. 
[21] CEM. Mapa da vulnerabilidade social da população da cidade de São Paulo. Zona Leste. São Paulo: Sas/ CEM/SESC/Cebrap/CEM, 2004.

[22] Caldeira, op. cit.
[23] Atualmente, os $14 \mathrm{~km}^{2}$ do distrito de Cidade Tiradentes abrigam cerca de 220 mil habitantes.

[24] O maior impulso às melhorias foi dado pela pressão política exercida pelos movimentos sociais, que na Zona Leste tiveram uma notável importância.

\section{Cidade Tiradentes - SÃo Paulo}

Emque medidaa situação Paraisópolis-Morumbi poderia sergeneralizada para toda a região metropolitana? Partindo do procedimento de buscar diferentes situações periféricas, o segundo caso etnográfico procurou distanciar-se das características de Paraisópolis, basicamente de sua proximidade espacial das fontes de recursos. Assim, fomos investigar uma localidade na extremidade do espaço metropolitano, no final da Zona Leste: a Cidade Tiradentes.

De todas as regiões da cidade de São Paulo, a Zona Leste é aquela que melhor se enquadra no que ficou conhecido na literatura como o padrão de urbanização "centro-periferia". À medida que se avança em direção "à periferia", ou quanto mais distante do Centro, a pobreza aumenta ${ }^{21}$, sendo esta lógica interrompida por alguns condomínios privados de classes média e alta, muitos deles com fortes esquemas de segurança privados como "enclaves fortificados", conforme a definição de Caldeira ${ }^{22}$. Essa disposição gradual da desigualdade explicita os processos de urbanização ligados à especulação imobiliária: a população que chegou primeiro a um determinado ponto reivindicou melhorias para esse local junto ao poder público. O resultado é a valorização de terrenos deixados vazios pelos especuladores. Como conseqüência, novas levas de migrantes foram obrigadas a procurar terrenos mais baratos e mais longe, logo, desprovidos de infra-estrutura.

Do ponto de vista do poder público, a preocupação com a Zona Leste cresceu na medida em que passou a ser considerada decisiva para qualquer pretensão eleitoral. Dentre os investimentos públicos realizados na Zona Leste nas décadas de 1970 e 1980, o mais paradoxal deles foi a construção de um enorme conjunto habitacional numa região batizada de Cidade Tiradentes. O local escolhido e o momento da construção expressaram a lógica estatal segregadora. A Cidade Tiradentes começou a se formar em 1975, em uma região de mata densamente fechada, a 25 quilômetros do centro do município de São Paulo, a uma considerável distância do último ponto de expansão da mancha urbana ${ }^{23}$. Se nos outros bairros desta macrorregião (a Zona Leste) as intervenções públicas ocorriam a reboque da pressão popular por melhorias ${ }^{24}$, a Cidade Tiradentes expressou o inverso, pois foi concebida e construída pelo poder público com a finalidade de, à primeira vista, realocar a população pobre de outros bairros do município de São Paulo e diminuir o déficit habitacional.

Embora o subtítulo acima ("Cidade Tiradentes - São Paulo") possa sugerir duas localidades distintas, na verdade, Cidade Tiradentes pertence administrativamente ao município de São Paulo. Contudo, a pesquisa constatou que o distrito, apesar da grande população, é tratado pela mídia como algo não muito diferenciado internamente e muito distante das características do "centro expandido" de São Paulo. 
Por outro lado, muitos moradores de Cidade Tiradentes, quando vão à região central do município, dizem que "Vão a São Paulo", como se sua percepção fosse de um apartamento da vida da cidade, mas ao mesmo tempo dependente dela. Cidade Tiradentes tem um emprego para cada 398 indivíduos ${ }^{25}$, o que tem por resultado o desgastante deslocamento diário de milhares de pessoas em direção às regiões centrais, $\mathrm{o}$ qual chega a demorar de quatro a cinco horas por dia no percurso casatrabalho-casa, por meio de ônibus, trem, metrô e van (ou perua).

Grosso modo, se levarmos em consideração a regularização fundiária, a Cidade Tiradentes pode ser dividida em duas: a "legal" e a "ilegal". A "legal" é composta de conjuntos habitacionais em terras públicas com cerca de $150 \mathrm{mil}$ habitantes. Ainda que planejada como área legalizada, uma vez que as terras pertencem ao poder público, boa parte dos moradores do distrito não tem a propriedade do imóvel em que vivem. São os moradores das ocupações, dos lotes irregulares, das favelas. Ao todo, 70 mil pessoas vivem nessa que pode ser chamada a Cidade Tiradentes "ilegal" 26.

Uma idéia generalizada sobre Cidade Tiradentes é a de que o distrito é um "depósito de gente". Removidos de outras favelas da cidade, beneficiados por programas habitacionais do governo, pessoas que não conseguem pagar o custo de vida de outros bairros. Ainda que haja exceções, o "irmorarna Cidade Tiradentes" quase sempre representou uma das últimas opções, quando a possibilidade de se manter em locais mais ou menos distantes do Centro, onde o custo de vida é mais alto, já não era mais factível. Este fenômeno, já analisado pela literatura ${ }^{27}$, refere-se à "inviabilidade" de moradia da camada mais pobre nos bairros periféricos consolidados. A paulatina melhoria das condições de habitação nesses bairros, expressa no acesso à infra-estrutura urbana e no aumento dos equipamentos públicos, resultou no custo mais alto para seus moradores, seja na elevação do preço dos bens de consumo destinados a essa população, seja no preço dos impostos territoriais. Este fenômeno econômico provocou a "expulsão" de uma parcela da população para locais mais baratos, desprovidos de infra-estrutura e de condições de moradia. Para os antigos moradores da periferia consolidada da Zona Leste que padeceram da "inviabilidade", a Cidade Tiradentes tem sido o destino e passa atualmente por um vertiginoso crescimento demográfico.

Mudar-se para um local distante, principalmente do trabalho, torna a vida ainda mais difícil, aumentando as reclamações e o desinteresse em assumir a responsabilidade pelo local onde se vive, e assim pouco se contribui para sua melhoria. As precárias condições materiais fazem da Cidade Tiradentes um local de passagem, onde as pessoas não querem ficar por muito tempo, pois representa um ponto descendente na trajetória dos indivíduos. Em Cidade Tiradentes,
[25] Ministério do Trabalho. "Relação AnualdasInformações Sociais/1999"; 〈www.mte.gov.br. Brasília: Ministério do Trabalho e Emprego, 2002), acessado em 27/11/2008.

[26] Usina.Plano de Ação Habitacional e Urbana/Cidade Tiradentes. Relatório Diagnóstico. Programa Bairro Legal. Sehab/CEM/USINA, 2003.

[27] Kowarick, Lúcio. Escritos urbanos. São Paulo: Editora 34, 2000 , p. 28; idem. A espoliação urbana. Rio de Janeiro: Paz e Terra, 1993; Bonduki, op. cit; Caldeira, op. cit. 
[28] Bonduki, op. cit.; Caldeira, op. cit.; Kowarick, $A$ espoliação urbana, op. cit.

[29] As partes mais centrais deste setor foram as principais áreas atingidas pelo investimento imobiliário. $\mathrm{Na}$ Marginal do Pinheiros a região ocupada pela favela Águas Espraiadas foi removida para dar lugar a um complexo de edificações para escritórios de negócios e espaços de entretenimento. constrói-se barato e vende-se barato porque o ônus de viver no bairro é alto. Esta lógica é um dos principais constituidores do fenômeno da segregação espacial, elemento fundamental para a compreensão do padrão centro-periferia da cidade de São Paulo ${ }^{28}$.

Diante deste quadro, a moradia é um dos temas centrais e sujeitos à ação tática. Se o financiamento público é a forma burocrática de posse dos apartamentos, existem outras formas de ocupação, como a simples invasão de apartamentos ainda não ocupados pelos proprietários (casos de investimento imobiliário, por exemplo), ou a invasão deliberada de terrenos previamente destinados à construção de conjuntos habitacionais. Desta forma, os invasores vão ser os primeiros a receber o financiamento do poder público.

\section{POPULAÇÃO DE RUA NO CENTRO}

Nosso primeiro caso tratou da relação entre uma favela (Paraisópolis) e um bairro rico (Morumbi) situados de forma contígua no espaço urbano. O segundo analisou uma localidade longínqua, na extremidade da mancha urbana (a Cidade Tiradentes). Por fim, voltamos a uma das centralidades da cidade, a saber, o Centro histórico e comercial e sua população de rua. As características mais gerais deste terceiro caso são a centralidade espacial e a mobilidade dos pobres.

Historicamente, o Centro de São Paulo sempre foi marcado pela presença conjunta de segmentos sociais provindos de diferentes estratos. Entretanto, isto começou a modificar-se quando, a partir dos anos 1960, iniciou-se um deslocamento do capital imobiliário, do investimento estatal e, por conseguinte, da centralidade do município em direção ao vetor sudoeste 29 . Este deslocamento foi resultado também de um conjunto de políticas públicas no qual a sucessão de intervenções tornou-se determinante para a crise do Centro. As políticas urbanas o trataram como um nó de articulação e passagem em uma grande estrutura viária. Por conseguinte, a popularização do Centro foi o produto de políticas estatais historicamente direcionadas para favorecer o acesso à região por meio do sistema de transportes. Este processo foi posteriormente chamado de "degradação", sobretudo por agentes preocupados em inverter tal quadro e tornar o Centro um local atraente para investimentos imobiliários, turísticos e culturais. Deste modo, vimos surgir nas três últimas décadas do século XX um Centro mais popular, que passou a exibir uma situação anteriormente restrita aos bolsões de pobreza da metrópole.

Mesmo com o deslocamento da centralidade dominante para o vetor sudoeste e a popularização da área, o Centro histórico e comercial permanece como um espaço urbano de fundamental importância na articulação do conjunto da metrópole. Nesta região há uma tensa coexistência entre dinamismo econômico e condições extremas de po- 
breza, e reúne numa só área um denso conjunto de características que a distingue de outros espaços da metrópole. Por ser uma nodalidade do sistema viário, o Centro tem o mais alto índice de circulação diária: lá passam cerca de 2,8 milhões de pessoas por dia (aproximadamente um quarto de toda a população da cidade). A região ainda concentra a maior taxa de vacância de toda metrópole, cerca de $20 \%$, e a maior taxa de oferta de empregos da cidade. E esta maior oferta de empregos representa a massa real de salários correspondente a cerca de um quarto de todo o município de São Paulo3o. Essa transformação do Centro em lugar de passagem para grande parte da população paulistana, somada ao pedestrianismo, fez com que as dificuldades relacionadas ao transporte automotivo estimulassem a circulação de transeuntes, especialmente de renda mais baixa, criando condições favoráveis ao desenvolvimento do comércio ambulante e, de maneira mais ampla, da geração informal de renda.

Como figuras liminares que diariamente coabitam o espaço público da região, os segmentos populares do Centro são fundamentais na reprodução da dinâmica local. Dentre eles, destacam-se a população de rua, uma pobreza espacialmente localizada no interior de um centro de recursos materiais. Em 1991, eram 3.392 pessoas nesta situação e, em 2003, o número saltou para 10.394. Atualmente, estima-se que superem os 11 mil, e que, segundo a mesma fonte ${ }^{31}$, a maior parte deste contingente populacional seja formada por pessoas que vivem nos distritos da Sé, República, Brás e Liberdade.

A dificuldade de fixação espacial é um de seus aspectos mais singulares. Devido à constante pressão local que sofrem (dos moradores próximos, de segmentos populares que se utilizam diariamente do espaço público urbano, da atividade policial e da coleta do lixo urbano que freqüentemente desmonta suas moradias improvisadas), podemos dizer que este segmento se encontra em constante processo de desterritorialização e exílio. Muitos dos moradores de rua são catadores de material reciclável e fazem das carroças suas próprias casas "ambulantes", demonstrando deste modo uma de suas características principais: a mobilidade.

A nomeação "população de rua" foi consagrada em 1992 com a publicação de uma pesquisa financiada pela prefeitura de São Paulo, na gestão do PT (1989-1992), sobre as pessoas que utilizavam as ruas como lugar de pernoite $e^{32}$. A pesquisa descobriu que, ao contrário do que se pensava, a maior parte não era constituída por migrantes recém-chegados ou nordestinos. Existiam famílias morando nas ruas egrande parte destas pessoas possuía uma trajetória de trabalho, ainda que fosse uma história profissional segmentada. Como conseqüência, as explicações para a "situação de rua" deixaram de se organizar unicamente através de uma matriz valorativa vinculada a julgamentos
[30] Emurb/CEM. Caminhos para o Centro: estratégias de desenvolvimento para a região central de São Paulo. Prefeitura Municipal de São Paulo/ Cebrap/CEM, 2004.

[31] SAS (Secretaria Municipal de Assistência Social), FIPE (Fundação Instituto de Pesquisas Econômicas). Censo dos moradores de rua da cidade de São Paulo. São Paulo, 200o; idem. Recenseamento dos moradores de rua da cidade de São Paulo. São Paulo, 2003.

[32] Vieira, Mac, Bezerra, E. e Rosa C. População de rua - quem é, como vive, como é vista. São Paulo: Hucitec, 1994. 
[33] A grande parte dos chamados "destoantes sociais" muitas vezes só possui em comum o estigma, aquele atributo dado à diferenciação vergonhosa (Goffman, Erving. Estigma: notas sobre a manipulação da identidade deteriorada. Rio de Janeiro: Guanabara, 1988). No caso da população de rua, o signo diacrítico de desaprovação que produziria uma suposta unidade a este todo fragmentado seria a própria rua.

[34] Vieira, Bezerra e Rosa, op. cit., pp. 93-94. morais e se voltaram para questões relativas à estrutura socioeconômica brasileira. Graças a referenciais analíticos oriundos de uma teoria social centrada no conceito de trabalho, o "mendigo" passou, então, a servisto como "trabalhador marginalizado".

O aumento populacional na década de 1990 foi acompanhado por uma maior publicidade e politização da questão. Em torno do mandato da então vereadora do PT Aldaíza Sposati, um conjunto de agentes sociais, entidades religiosas e ONGs estabeleceram nas gestões do PPB (1993-1996 e 1997-2000) uma plataforma comum de reivindicações por uma lei que tratasse da população de rua. $O$ projeto de lei produzido atravessou a década de forma conturbada e só foi regulamentado em 2001, como o primeiro ato político da prefeitura na gestão do PT de 2001-2004.

Aquilo que atualmente chamamos de população de rua caracterizase por ser uma categoria genérica, um estereótipo que tenta dar conta de um todo extremamente heterogêneo e diversificado de categorias identitárias que nem sempre estão articuladas entre si33. As mais conhecidas são: os trecheiros, os pedintes, os sem-teto, os albergados, os ditos "loucos", os meninos de rua e os catadores de materiais recicláveis. A principal maneira de diferenciação na composição social desta população heterogênea e multifacetada vinculada ao universo da rua é o tempo.Assim são identificadas pelo menos três situações diferentes: ficar na rua (circunstancialmente), estar na rua (recentemente) e ser da rua (permanentemente) 34 . De um lado a outro deste contínuo é possível compreender a realidade de pessoas que se utilizam da rua e dos albergues de forma circunstancial ou como modo de vida. A despeito do desconhecimento geral que se possui sobre o perfil dos albergados, sabe-se que há uma intensa e contínua circulação entre diferentes instituições. Algumas vezes qualificados informalmente como "trecheiros de albergue", esta é uma população circunstancialmente de rua. Em depoimento, um usuário de albergue falou de sua "teoria dos oito anos", segundo a qual seria possível viver este período de tempo sem precisar pagar aluguel e alimentação, apenas "pulando" de instituição em instituição. Esgotando o tempo-limite de permanência em um albergue, taticamente os usuários se mudam para outro, ou então voltam para a rua.

Como dito inicialmente, as situações de contraste de cada etnografia foram sendo produzidas em interlocução umas com as outras, de modo que cada material de campo interpelou e foi interpelado pelos outros dois. O objetivo nãoé o de se limitar ao campo das semelhanças e diferenças das situações, mas derivar da comparação delas alguns 
mecanismos comuns e dinamizadores deste processo de atenuação da pobreza e reprodução da desigualdade social. Os mecanismos são: a violência simbólica, a vulnerabilidade política e a qualidade dos vínculos sociais. Existem outros processos que contribuem para o jogo oscilante entre atenuar e reproduzir, mas estes três nos pareceram mais gerais e capazes de englobar outras dimensões observadas em campo.

\section{A VIOLÊNCIA SIMBÓLICA: ENTRE A (IN)VISIBILIDADE E O ESTIGMA}

Partindo do quadro heterogêneo da pobreza, as pesquisas de campo procuraram investigar - além dos aspectos propriamente materiais dos circuitos de reciprocidade (relações, agentes, benefícios, serviços) - as representações simbólicas sobre as localidades tanto de seus moradores quanto do restante da cidade, expressas na mídia, na relação com o Estado e na opinião pública. Dessa forma, constatamos que a articulação entre visibilidade e estigma no espaço social são fatores importantes na obtenção ou não de recursos e na reprodução da desigualdade.

Paraisópolis é o contexto onde o estigma é mais negociável, dado o paradoxo de sua localização geográfica. Em relação a outros bairros populares e/ou favelas, morar em Paraisópolis acrescenta um relativo status perante as outras favelas por causa da proximidade com o Morumbi. Entretanto, seus moradores são estigmatizados pelos moradores deste bairro. Na verdade, a vizinhança rica mantém uma atitude ambígua com Paraisópolis. Em um espaço curto de duas quadras é possível deslocar-se do ambiente populoso e congestionado de Paraisópolis e entrar nas ruas vazias e tortuosas do Morumbi, onde se vê os moradores locomoverem-se de carros enquanto os empregados se deslocam a pé, uma vez que não há transporte público circulando por seu interior. Os condomínios e mansões do Morumbi têm esquemas de segurança privados que dificultam o acesso dos moradores da favela. Em resumo, há uma relação de "evitação" e "interação" entre Paraisópolis e Morumbi dependendo do plano que se estabeleça entre estes dois universos. Nos planos do trabalho e da assistência há "interação" enquanto nos do lazer, valores, gostos, parentesco e amizade há "evitação". Neste sentido, a sugestiva idéia de Caldeira sobre os "enclaves fortificados" como demarcadores de distância social deve ser relativizada quando se refere às relações de trabalho e de assistência.Apesar de uma arquitetura de segregação, Morumbi e Paraisópolis estão parcialmente conectados por circuitos de relações que transformam a localização da favela em uma "estrutura de oportunidades".

Com relação à Cidade Tiradentes, impôs-se o estigma da violência. Muitas vezes ouvimos a expressão "Cidade Tiroteio" para denominar o bairro. Entretanto, levando em consideração os 96 distritos que 
[35] CEM.Mapadavulnerabilidadesocial da população da cidade de São Paulo. Zona Leste. São Paulo: Sas/CEM/ SESC/Cebrap/CEM, 2004, p. 48 .

[36] Depoimento extraído do documentário Moro em Tiradentes, dirigido por Henry Gervaiseau com base no relatório de pesquisa de Tiarajú D'Andrea (Redes sociais em Cidade Tiradentes. São Paulo: relatório, Cebrap/Finep, 2005).

[37] Ibidem. conformam o município de São Paulo, e fazendo uma escala do mais ao menos violento, de acordo com a taxa de homicídios de indivíduos de 15 a 29 anos, a Cidade Tiradentes ficaria em $55^{\circ}$ lugar35. Não se pretende com a apresentação deste dado negar um contexto de situação de violência, mas indicar a desproporção criada pelo estigma do lugar e o que ocorre nele. Longe, pobre, sem história, sem emprego, dependente de políticas públicas e com fama de violenta, Cidade Tiradentes é percebida (e parcialmente se percebe) por um somatório de características estigmatizantes.

Fruto das classificações legitimadas socialmente, o estigma da pobreza é reproduzido pelos formadores de opinião, como moradores de bairros de classe média, o poder público, a imprensa, ou mesmo os próprios moradores dos bairros populares que atribuem aos outros o adjetivo que pesa sobre si. Como negar a violência é impossível, mais fácil é dizer que ela não acontece em seu bairro. Disto resultam duas máximas nativas: "o pobre ésempre o outro" e "lá,é mais violento".

A classificação simbólica não está dissociada do mundo material na medida em que existem conseqüências práticas. Um dos exemplos mais freqüentes dos "efeitos do estigma" refere-se à seleção de pessoas para a obtenção de um emprego. Dizer-se morador de Paraisópolis pode ser um indício favorável, sobretudo no Morumbi, dada a proximidade, e facilita ainda mais se o candidato a empregado tiver algum parente ou vizinho trabalhando no entorno rico que o possa indicar. A existência de várias ONGs locais também aumenta as chances de entrada no mercado de trabalho, por meio de empregos diretos ou de cursos de capacitação. Fora da região, a enunciação de Paraisópolis como endereço pode ser um fator inibidor à contratação. No caso de Cidade Tiradentes é comum os moradores omitirem o endereço de moradia devido aos atributos negativos já enunciados, sobretudo na busca do emprego. A distância da Cidade Tiradentes aos postos de trabalho faz com que seus moradores dêem endereços falsos, ou o de um amigo ou familiar, ao possível novo empregador. $\mathrm{Na}$ falta de uma ajuda, vale simplesmente enunciar "Moro em Itaquera" 36 . A construção/descontrução de identidades obedece a uma lógica geográfica e relacional, estruturada de acordo com o potencial de cada região na aquisição ou não de bens simbólicos que propiciam a aquisição ou não de bens materiais, conforme seu status ou seu estigma ${ }^{37}$.

Por um lado, a dificuldade de conseguir emprego deve-se à estigmatização da localidade, que é extensiva a seus moradores; por outro, decorre de um cálculo feito pelo empregador, sobretudo das diaristas e empregadas domésticas. Em razão da distância, até o início dos anos 2000, o empregador devia pagar mais de uma passagem de ida e volta às empregadas. Ou elas escondiam, ou negociavam com a "patroa" o pagamento das passagens. Como contraponto, cabe destacar o impac- 
to positivo, durante a gestão da Marta Suplicy, do programa de transporte Bilhete Único, que atacou em boa medida a estrutura limitadora da circulação dos mais pobres.

Diferentemente dos moradores de Paraisópolis ou Cidade Tiradentes, onde a enunciação do local de moradia destaca seus aspectos negativos, no caso da população de rua, o estigma é criado de forma interacional no fluxo dos encontros cotidianos entre as pessoas. Num momento em que a quase totalidade de estudos brasileiros sobre pobreza urbana voltava-se para a periferia, Stoeffels debruçou-se sobre a marginalidade do centro da cidade tentando interpretar o significado existencial e estrutural do que considerava como o "ser mendigo" 38 . O que vimos nas três últimas décadas foi uma metamorfose deste ser. O universo das ruas alterou-se amplamente e seus habitantes também. Uma reconfiguração da imagem daquele antigo mendigo, cuja identidade estava ligada à prática da mendicância e comumente associada ao fracasso moral individual, iniciou-se na década de 1980 e consolidou-se no início deste século. Hoje, parte desta população está politicamente mobilizada para transformar-se qualitativamente com a finalidade de ser reconhecida publicamente por meio de outras imagens, significados e nomes; nos termos de Honneth 39 , ela busca ser "reconhecida". Noção mais ampla do que visibilidade, reconhecimento significa ser visto e percebido como uma identidade com valor social, o que resulta em indivíduos ou grupos portadores de direitos.

Tendo em vista os três casos, a visibilidade em si pode gerar tanto estigma quanto reconhecimento. Cada situação periférica articula na prática estes termos. Paraisópolis é assistida porque, entre outros fatores, é uma pobreza visível. Mesmo assim é considerada uma favela. Os moradores calculam os benefícios e as perdas de se identificar como sendo de Paraisópolis dependendo de com quem estiverem falando. Cidade Tiradentes é invisível para o centro expandido de São Paulo, do ponto de vista da dinâmica urbana, dos meios de comunicação, da opinião pública, da atenção do Estado e de ONGs etc. Na verdade, Cidade Tiradentes oscila entre a invisibilidade e, para aqueles que a conhecem, a visibilidade estigmatizada. Entretanto, e por fim, a visibilidade do estigma pode ser utilizada como símbolo de reivindicação de direitos e de assistência social. Disto decorreu a formação do campo institucional em torno da população de rua do Centro de São Paulo4º. Inverte-se o sentido: de signo de excluído passa-se a signo de portador de direitos. Com diferentes maneiras de se tornar visível, Paraisópolis e a população de rua construíram uma "estrutura de captação" de recursos públicos, privados e do terceiro setor.

No caso dos movimentos dos moradores de rua, a tática adotada é a da visibilidade desestigmadora. Trata-se de uma categoria identitária "codificada" 41 e com valor social "reconhecido" 42 . Codificação e
[38] Stoffels, Marie Ghislaine. Os mendigos na cidade de São Paulo - ensaio de interpretação sociológica. Rio de Janeiro: Paz e Terra; 1977.

[39] Honneth, Axel. "Invisibilité: sur l'épistémologie de la 'reconnnaissance"'. In: La société du mépris: vers une nouvelle Théorie critique. Paris: Éditions La Découverte, 2006, p. 225.

[40] De Lucca, Daniel. A rua em movimento: experiências urbanas e jogos sociais em torno da população de rua. São Paulo: dissertação de mestrado, FFLCH-USP, 2007.

[41] "A codificação é uma operação de ordenação simbólica, ou de manutenção da ordem simbólica, que em geral compete às grandes burocracias estatais" (Bourdieu, Pierre. "A codificação". In: Coisas ditas. São Paulo: Brasiliense, 2004, p. 101.

[42] Honneth, op. cit. 
reconhecimento podem se aproximar neste sentido; contudo, como mesmo afirma Honneth, seu conceito pressupõe uma dimensão normativa e substantiva: uma identidade dotada de valor, mas que também tende à cristalização. E o perigo é cair no paradoxo colocado por Bourdieu: positivar uma identidade que o estigmatizou por primeiro. Ao analisar os usos do termo "povo", ele pergunta:

[... ] se, para resistir, não tenho outro recurso a não ser reivindicar aquilo em nome do que eu sou dominado, isso é resistência? Segunda questão:quando, ao contrário, os dominados se esforçam por perder aquilo que os marca como "vulgares" e por se apropriar daquilo em relação a que eles aparecem como vulgares (por exemplo, na França, o sotaque parisiense), isso é submissão? Acho que esta é uma contradição insolúvel 43 .

\section{VULNERABILIDADE POLÍTICA: AS MULTIFACES DO ESTADO}

Nos três campos etnográficos o Estado apresenta-se como um importante ator e interventor; contudo, percebe-se que muitas de suas ações produzem efeitos ambíguos. De diferentes maneiras observa-se como determinadas práticas estatais alternam-se e articulam simultaneamente segregação e distribuição de recursos. A ação política de "dar e tirar", pensada aqui como pólos extremos de um continuum de combinações e dosagens, está diretamente conectada a outros fatores, tais como a presença ou a ausência de organizações do terceiro setor, e às intempéries das políticas de governo, que variam de acordo com cada gestão municipal.

Tido como um "laboratório de políticas públicas", segundo representantes da gestão Marta Suplicy (2001-2004), Cidade Tiradentes padeceu dos desencontros da política pública nesse período. De maneira geral, a preocupação do poder público com a Zona Leste cresceu bastante no período pós-regime militar. Como esta macrozona foi e é o principal reduto do eleitorado paulistano, os investimentos nela são decisivos para qualquer ambição política no âmbito dos poderes Executivo e Legislativo. Dessa forma, após a redemocratização do país, uma série de investimentos públicos foi realizada na região. Contudo, como os condomínios e a infra-estrutura urbana construída pelo Estado não deu conta da população, que lá se estabeleceu em invasões e favelas, há sempre a impressão de que as melhorias pleiteadas junto ao poder público são uma corrida contra o tempo. Nota-se também uma sobreposição de políticas públicas das três esferas: municipal, estadual e federal, sem existir uma adequada articulação entre elas. Cada uma dessas esferas tem uma arqueologia própria de intervenções pouco articuladas e marcadas por descontinuidades. 
Devidoà desarticulação entre os variados projetos habitacionais na escala municipal, estadual e federal, a paisagem de Cidade Tiradentes tem um traçado descontínuo, fruto da sobreposição de intervenções no espaço urbanizado. Em alguns lugares, tem-se a impressão de ser uma "favela de conjuntos habitacionais" por causa da maximização do uso dos terrenos. Ao promover políticas sociais de habitação num lugar extremamente distante das centralidades e dos principais espaços urbanos dotados de benefícios públicos e oportunidades de trabalho, o poder público realiza política de inclusão ao mesmo tempo que reforça a segregação já existente na cidade 44 . Outro paradoxo das ações estatais é o procedimento do sorteio na entrega dos apartamentos aos novos proprietários como forma de ocupação democrática dos deslocados de outras regiões da cidade, como ocorreu no governo Mário Covas. Entretanto, este procedimento acentuou a fragmentação das redes anteriores (de parentes ou vicinais) à ocupação da Cidade Tiradentes. Se em Paraisópolis era possível contar com circuitos de reciprocidade mantida na migração, em Cidade Tiradentes isto é desestruturado por uma "política pública igualitária".

Com relação à população de rua, o poder público codificou uma legislação que fez da categoria rua um universo aberto e difuso. A partir da formalização e oficialização, ainda que imprecisa, deste novo sujeito político, foi possível edificar um conjunto interligado de práticas políticas, normas jurídicas e técnicas propriamente psicológicas, pedagógicas e assistenciais relativas ao trato com este público. $\mathrm{O}$ Estado, ao produzir uma classificação oficial e homologar o direito destes sujeitos, definidos e codificados unicamente a partir do signo rua, formalizou também as maneiras pelas quais estes deveriam ser abordados. E para cumprir esta finalidade, o poder municipal necessitou garantir a instalação e a manutenção de uma rede de serviços pautada por relações de parceria e por convênios com associações civis sem fins lucrativos. Em resumo, ao mesmo tempo em que emerge um novo sujeito de direitos em São Paulo, articulado a este, surgem também instituições, práticas, discursos, técnicas e formas próprias de saber/poder capazes de sujeitá-los e ordená-los. No centro de São Paulo há uma densa e complexa rede de interesses, conflitos e atores da qual o Estado é mais um personagem.

A "Lei de Atenção à População em Situação de Rua" produziu um surpreendente aumento da rede de atendimento, ampliação dos equipamentos de apoio e criação de novas parcerias e convênios de entidades do terceiro setor com a prefeitura municipal. $O$ número de leitos disponíveis em albergues quase duplicou no período, de maneira que boa parte do crescimento total da população em situação de rua, nos últimos cinco anos, é atribuída ao aumento dos "albergados", que entram no cômputo geral da categoria. Nas duas
[44] Ao incentivar a remessa de todo um contingente populacional para a fronteira urbana, o poder público coloca-se numa situação em que necessita levar, também, a cidade consolidada, com todos os seus serviços, equipamentos e redes técnicas, para esta região, gerando, desta maneira, um aumento dos gastos públicos. 
últimas contagens, de 2000 e 2003 , percebe-se como a variação da população que usava a rua como lugar de pernoite foi baixa, enquanto o número de pessoas que utilizam os albergues como local de pernoite aumentou em cerca de $70 \%$.

Apesar da lei explicitar a necessidade da construção de uma rede de atendimento mais plural e pautada por metodologias de trabalho não assistenciais, o que ocorreu na gestão municipal do PT foi o fortalecimento desta rede mediante uma política de criação de albergues, em detrimento de outras formas de abordagens mais localizadas e voltadas para a convivência e a criação de laços mais estreitos entre os usuários, como as moradias provisórias e as casas de convivência. $\mathrm{O}$ albergue tornou-se a principal política pública voltada a este segmento, tendo sido concebido originalmente como uma forma de abrigo provisório para as pessoas que estivessem saindo da rua. O que foi construído para ser um lugar transitório e de passagem tornou-se um local de permanência e moradia para muitos. É possível aferir que o albergue tem se tornado um potente mecanismo de recrutamento de pessoas para o mundo da rua. Não unicamente operando como uma "porta de saída", mas servindo também como "porta de entrada" para este universo.

Apesar das intempéries eleitorais que afligem mais os mais pobres, a mudança na gestão municipal em 2004 (administração José Serra do PSDB) não significou de imediato uma ruptura com as formas de atendimento anteriores e nem com as políticas públicas até então voltadas para este setor da população.A presença de um enorme aparato de atendimento já construído, com convênios e parcerias, ou seja, a existência de um campo relativamente autônomo e estruturado, interligando um complexo conjunto de atores envolvidos com o tema, dificultou uma possível ruptura política brusca. O mesmo não aconteceu em Cidade Tiradentes, onde Marta Suplicy havia recebido cerca de 60\% dos votos na disputa com José Serrá em 2004. Nossa percepção geral é de que Cidade Tiradentes deixou de ser o "laboratório" da gestão municipal.

Paraisópolis, relativa e proporcionalmente à população de rua e ao distrito de Cidade Tiradentes, é o local que recebe mais recursos (privados e públicos). No entanto, constata-se a instabilidade da posse da terra em Paraisópolis devido aos interesses imobiliários, que buscam a remoção de uma boa parcela dos moradores. A oscilação de períodos mais ou menos favoráveis à remoção ocorre conforme a articulação entre estes interesses e os agentes políticos da máquina do município e do estado. Nas gestões municipais (entre 1989-1992 e 2001-2004) petistas houve significativos investimentos no local e na população enquanto nas gestões pepebistas (entre 1993 e 2000) o medo da remoção e o descaso nos serviços de limpeza e transporte tornaram a vida mais difícil. 
Assim, as prioridades das ações estatais dependem em parte do cálculo político sobre a possibilidade de um local ser convertido minimamente em base eleitoral. Em maior ou menor intensidade, a quase totalidade das ações de um governo em qualquer parte do município levará em conta o rendimento eleitoral, e isto é mais característico dos lugares mais pobres, que são submetidos mais às políticas de governos do que à rotina da máquina estatal, cujo resultado é uma trajetória de instabilidade. A alternância no poder pode significar ganhos ou perdas materiais consideráveis. Castel sugere pensar a pobreza não somente a partir da dimensão econômica, mas também por meio dos vínculos sociais que geram maior integração (família, vizinhança, associações civis, igrejas etc.) 45 . Entretanto, diante dos casos etnografados, a vulnerabilidade deve ser pensada também em termos políticos ${ }^{46}$, seja pela alternância dos governantes, seja pela qualidade dos vínculos estabelecidos com eles.

\section{A QUALIDADE doS VÍNCULOS SOCIAIS: ENTRE A PROTEÇÃO E A LIMITAÇÃo}

Em seu estudo sobre os efeitos das redes sociais, Granovetter problematiza o pressuposto da virtuosidade dos laços sociais47. Para o autor, as redes sociais muito coesas e densas tendem à "redundância" das relações a partir de um determinado ponto.A "redundância" limita a circulação de bens, pessoas, informações etc. Em contrapartida, a pouca necessidade de fidelidade dos laços fracos permite um alcance maiore diferenciado de relações sociais.Éa "fortaleza dos laços fracos". Uma parte do nosso argumento sobre os circuitos de reciprocidade afirma a positividade dos laços sociais na proteção dos indivíduos ou dos grupos em situação de vulnerabilidade. Seguindo a proposição de Castel de não pensar a pobreza somente a partir da dimensão econômica, constatamos que apesar da situação de vulnerabilidade de Paraisópolis existem vários circuitos de reciprocidade trabalhando a favor de uma maior integração social ${ }^{4}$. Se a virtuosidade dos circuitos era nosso pressuposto inicial, sobretudo após a pesquisa em Paraisópolis, outros exemplos demonstraram a existência de boas e más conexões, que podem significar tanto proteção quanto limitação da mobilidade social.Assim, gostaríamos de problematizar os ganhos e as perdas nos circuitos de reciprocidade: a vizinhança, a família e as associações de assistência.

Com relação ao circuito formado pela vizinhança, como lidar com o contexto de violência de boa parte dos lugares pobres? Embora Paraisópolis, Cidade Tiradentes e o Centro de São Paulo não sejam tão violentos quanto a percepção que se tem destes lugares, existe um patamar de violência que não pode ser ignorado. Na relação dos moradores de Cidade Tiradentes com a violência não se pode deixar
[45] Castel, Robert. “Del'índigence à l'éxclusion, la désaffiliation: précarité du travail et vulnérabilité relationnelle". In: Danzelot, Jacques (org.). Face à l'éxclusion le modèle français. Paris: Esprit, 1991.

[46] Kowarick, L. "Viver em risco: Sobreavulnerabilidadeno Brasilurbano". Novos Estudos, nº63, julho de 2002.

[47] Granovetter, Mark. "The strenght of weak ties". American Journal of sociology, v. $78, \mathrm{n}^{\circ}$ 6, 1973, pp. $1360-$ 80.

[48] Almeida e D' Andrea, “Pobreza e redes sociais em uma favela paulistana", op. cit. 
[49] Zaluar, A. A máquina e a revolta. São Paulo: Editora Brasiliense, 1994 , p.144.

[50] Ibidem. de considerar que a adesão ao tráfico acontece devido ao alcance e espraiamento das redes de contato com as organizações criminosas, desdobrando-se na já famosa frase "todo mundo conhece alguém envolvido com o 'movimento"'. As estratégias de sociabilidade sem adesão podem realizar-se na forma de evitação com conivência forçada, expressa em frases do tipo "aqui não tem nada pra fazer, mas tem muita malandragem. O melhor jeito é conhecer os cara sem se envolver", ou em convivência pacifica, manifesta em atitudes de respeito entre bandido e comunidade, como já relatado em outros trabalhos49. Ambos os casos, a evitação e a convivência demonstram a necessidade de "conhecimento com abandidagem", ou seja, o necessário estabelecimento de uma relação. Se no primeiro caso a evitação é uma forma de não envolvimento e tentativa de garantia de segurança pelo afastamento, o "trabalhador honesto" avalia que a melhor forma de estar seguro é justamenteestar junto, respeitar sem julgar eestabelecer laços de confiança, sem estar envolvido na negatividade da rede.

Se as condições objetivas do local são um terreno propício para a busca de formas não convencionais de sobrevivência, um elemento explicativo para a adesão às práticas ilegais está relacionado com o acesso ao consumo, sobretudo entre os jovens, expressando-se na ostentação de roupas, carros, mulheres. Ou seja, signos de distinção em relação à população da qual se faz parte. A sensação de poder é reforçada pela admiração dos pares, das mulheres e do temor dos inimigos, o que Zaluar5o define como o éthos do guerreiro ao pensar a sociabilidade dos traficantes em Cidade de Deus, no Rio de Janeiro. A participação dos moradores direta ou indireta no tráfico é mínima em qualquer localidade, no entanto, esta sociabilidade forçada com a vizinhança do tráfico confere insegurança e indefinição à trajetória dos indivíduos, principalmente dos homens mais jovens. A maior parte dos depoimentos, sobretudo das mães, fala do medo dos filhos serem atraídos para o tráfico, não apenas como consumidores, mas como participantes diretos ou laterais ao comércio do "movimento". Já há algum tempo o termo utilizado com maior freqüência é "firma", e comumente os adolescentes e jovens envolvidos com o tráfico referem-se às suas atividades juridicamente ilícitas como "trabalho". Em resumo, a vizinhança nestas localidades, regra geral, é percebida como perigosa e da qual as pessoas devem proteger-se.

O segundo circuito de reciprocidade que deve ser problematizado é o familiar. Na observação de Paraisópolis e Cidade Tiradentes privilegiaram-se as famílias por serem um lugar de articulação de diferentes circuitos de relações que cada membro de um domicílio mobiliza, além da própria relação familiar. Em razão do acesso à variedade dos circuitos de reciprocidade, as famílias configuram-se como um conjunto de dimensões (as políticas públicas, o mercado de trabalho e as 
relações pessoais) que são equacionadas no seu interior. A pobreza e a mobilidade, ascendente ou descendente, se reproduzem na estrutura familiar mais do que nos indivíduos atomizados.

Verificamos em campo que a família é uma espécie de compensador que suaviza as diferenças geracionais. A família possibilita uma redistribuição e equilíbrio das dificuldades individuais. Pensada desta forma, ela é um ativo que age como uma rede de proteção; entretanto, esta concepção virtuosa das relações familiares pode se inverter quando vista de uma posição específica na rede familiar. Quando os postos de trabalho ficam mais restritos aos mais velhos, a família pode representar um peso para os mais jovens, que ficam limitados na mobilidade social, mesmo tendo passado por processos de capacitação educacional e profissional. Se o saldo do equacionamento das necessidades e conquistas materiais no interior de uma rede familiar tende a ser positivo (atuar como proteção social), do ponto de vista de algumas posições (no caso, os mais jovens) um limiteéestabelecido. Ovínculo aqui éum peso.

Por fim, se Paraisópolis e Cidade Tiradentes tiveram como focos principais de investigação as famílias e a vizinhança, como tratar os circuitos de reciprocidade dos moradores de rua? Em suma, sabemos que a qualidade de seus laços é fraca, mas qual o seu alcance e como operam? O caráter nômade da população de rua implica a enorme dificuldade de manutenção dos vínculos sociais mais perenes. A trajetória pessoal destes sujeitos é comumente marcada por um contínuo percurso de desligamento social que desemboca na rua ${ }^{51}$, considerado o estágio último e de valor simbólico negativo, de modo que suas histórias de vida são marcadas por processos de rupturas socioafetivas e econômicas. Suas histórias de vida caracterizam-se por sucessivas perdas, um percurso gradativo de quedas e lesões sociais. Porém, os rumos das histórias não são homogêneos e nem predeterminados. A pessoa pode ir e voltar para a rua várias vezes, pode ir e nunca mais sair, pode também ir para a rua, sair dela para nunca mais voltar (este último é um percurso muito mais complexo e difícil, além de envolver a atuação de outros agentes, tais como padres, familiares, clínicas de recuperação, possibilidades de trabalho e redes de atendimento pelo qual o sujeito passa eé "reformado") 52 .

Apesar da precariedade dos vínculos sociais entre os moradores de rua, faz algum tempo que se desenha em torno deles uma rede de assistência envolvendo algumas religiões (principalmente a Igreja católica), ONGs, voluntários, assistência social estatal, movimentos sociais etc. Castel53 chama esta parcela da população de "supranumerários", um contingente populacional sem funcionalidade no mundo do trabalho. Eles seriam o ponto de chegada de um processo de vulnerabilidade imposto por uma nova ordem nas relações de trabalho
[51] Paugam, Serge. Oenfraquecimento e a ruptura de vínculos sociais. Petrópolis: Vozes, 1999.

[52] De Lucca, op. cit.

[53] Castel, R. As metamorfoses da questão social: uma crônica do salário. 3-ed. Petrópolis: Vozes, 1995. 
que paulatinamente retira a rede de proteção social. Entretanto, para a pesquisa sobre os moradores de rua interessou-nos não somente $o$ percurso da perda, mas também e propriamente o ponto de chegada nele mesmo. Isto é, pensar os moradores de rua não como um fim, um resíduo ou uma passagem (na medida em que estas pessoas acabam morrendo mais novas do que o restante da população), mas como um padrão permanente no contexto da pobreza urbana de São Paulo.Eaqui se encontra o terceiro circuito de reciprocidade a ser problematizado.

Construiu-se um campo institucional no qual há uma disputa pela fala legítima sobre a população de rua. O surgimento desta ampla rede de assistência e associativa deve-se em boa medida à visibilidade crescente desta parcela da população nas partes centrais do município. Esta se move segundo a codificação encontrada na legislação e nos financiamentos públicos que se tornam indutores de práticas sociais. Para tanto, é necessário fixar uma identidade reivindicatória (morador de rua, sem-teto, sem-terra etc.), desestigmatizando-a dos seus atributos de baixo valor simbólico, com a finalidade de ter acesso a recursos materiais. Isto é, a possibilidade de atração de investimentos da população de rua está em transformar a classificação negativa em símbolo da reivindicação.

Se a estratégia do movimento de moradores de rua, por um lado, contribui na formação de uma rede de assistência; por outro, a prática de geração de renda pela reciclagem do lixo, por exemplo, fixou o morador de rua na rua. Pelo Centro de São Paulo, na região do Glicério por exemplo, os pontos de reclicagem de lixo construídos por $O N G$ s e da prefeitura foram construídos literalmente debaixo da ponte ou em ruas sem saída. Não se trata de uma política propriamente de retirada da população da rua (vide o aumento dos leitos em albergues), mas de uma melhoria na captação de renda ao enquadrá-la funcionalmente na circulação econômica, sobretudo na reciclagem do lixo produzido pela riqueza do Centro. A proliferação de albergues e a economia do lixo permitiram a emergência de uma nova forma de "estar nas ruas". Mora-se e trabalha-se na rua. Em resumo, se as redes protegem, sobretudo as familiares e de assistência, elas também limitam; de forma geral, elas sustentam, mas não geram com freqüência um processo de mobilidade ascendente devido à qualidade dos seus vínculos.

\section{CONSIDERAÇÃO FINAL}

Nossa primeira situação tratou da relação entre uma favela e um bairro rico localizados lado a lado. Na segunda, analisou-se uma localidade na extremidade da mancha urbana. Por fim, voltamos a uma das centralidades da cidade e sua população de rua. Do ponto de vista do espaço físico, são heterogêneas as distâncias sociais: contígua, lon- 
gínqua e contínua, respectivamente. Os três casos apresentam alguns mecanismos comuns mas com arranjos específicos (situados), cujo resultado é a diferenciação da própria pobreza urbana. Neste sentido, ela é entendida em sua diversidade interna e em relação aos outros estratos sociais. Nossa estratégia comparativa foi estabelecer extremos analíticos para refletir, por meio da pesquisa etnográfica, acerca das mediações e transversalidades do jogo social entre a relativa melhoria da pobreza e a reprodução das distâncias sociais. Estas duas linhas de força têm sentidos analíticos opostos, mas imbricados em um mesmo processo social. Voltando à distinção inicial de Certeau entre estratégia e tática, em todos casos analisados, observou-se uma estrutura desigual, que situa parcelas da população na periferia do espaço social, onde não podem agir a partir de um "lugar próprio", o que limita o ritmo e o alcance das melhorias, sempre em desvantagem aos outros estratos sociais.

RONALDO DE ALMEIDAé professor do Departamento de Antropologia da Unicampe pesquisador do Cebrap.

TIARAJÚ D'ANDREAé mestre em Sociologia pela USP e assistente de pesquisa do Cebrap.

DANIEL DE LUCCA é mestre em Antropologia pela USP e assistente de pesquisa do Cebrap.

Recebido para publicação

em 17 de novembro de 2008.

NOVOS ESTUDOS

CEBRAP

82, novembro 2008

pp. 109-130 